\title{
A "vida de assentado" na visão dos jovens da comunidade 8 de junho, Laranjeiras do
}

Sul - PR

Francieli Campos ${ }^{1}$

\section{Resumo}

O trabalho tem como objetivo apresentar a experiência de vida dos jovens que residem, sobrevivem e dependem da produção e reprodução das atividades produtivas agrícolas e nãoagrícolas do Assentamento 8 de Junho localizado em Laranjeiras do Sul - PR. Os jovens envolvidos em disputas por terra, e que vivem no espaço dos assentamentos despertam a convivência social, política, cultural, sentimental e pessoal ainda na infância, e isso passa a ser uma condição necessária para sua inclusão na dinâmica cotidiana da comunidade assentada. No caso desse estudo e baseado em diálogos e informações repassadas pelo público entrevistado foi possível encontrar uma realidade com jovens empenhados a se inserirem nas oportunidades oferecidas pela comunidade para permanecer nas atividades do campo, e junto com a comunidade tem procurado desenvolver atividades que sustenta o lote do assentamento como meio de sobrevivência futura.

Palavras-chave: Desenvolvimento rural, trabalho no campo, juventude, qualidade de vida.

\begin{abstract}
The work aims to present the life experience of young people who live, survive and depend on the production and reproduction of agricultural productive activities and non-agricultural Assentamento 8 de Junho located in Laranjeiras do Sul - PR. Young people involved in land disputes, and living within the settlements promotes social harmony, political, cultural, sentimental and personal in its infancy, and it becomes a necessary condition for inclusion in the daily dynamics of the settler community. In the case of this study and based on dialogue and information passed on by the responders were unable to find a reality with young people engaged to insert the opportunities offered by the community to remain in the activities of the field and with the community has sought to develop activities that sustains the lot of the settlement as a means of future survival.
\end{abstract}

Keywords: Rural development, fieldwork, youth, quality of life

\footnotetext{
1 Mestre em Desenvolvimento Regional e Agronegócio, Universidade Estadual do Oeste do Paraná (UNIOESTE). Email: frandecampos@yahoo.com.br
} 
Recebido em: Setembro, 2014

Aceito em: Junho, 2015

Para citar este artigo:

CAMPOS, FRANCIELI; A "vida de assentado" na visão dos jovens da comunidade 8 de junho, Laranjeiras do Sul - PR". In: Revista Intratextos, 2014, vol 6, no1, p. 51-67 DOI: http://dx.doi.org/10.12957/intratextos.2014.13016

\section{Introdução}

Com esse trabalho se objetiva apresentar a experiência de vida de jovens que residem, sobrevivem, dependem da produção e reprodução agrícola e não-agrícola do Assentamento 8 de Junho localizado no município de Laranjeiras do Sul - Paraná.

O Assentamento 8 de Junho pertence ao Movimento dos Trabalhadores Sem Terra MST, o qual está localizado no Território da Cantuquiriguaçu na porção Centro-Sul do Paraná as margens da rodovia BR 253. Um local que desenvolve atividades não-agrícolas a partir do trabalho de uma panificadora produtora de pães e massas em geral. Com apoio da Universidade Federal da Fronteira Sul - UFFS, entidades designadas pelo Movimento dos Trabalhadores Sem Terra - MST e entidades públicas, as famílias de modo geral trabalham com leite, e desenvolvem atividades monoculturas, como: soja, milho, trigo e fumo. Além disso, existem algumas famílias que se dedicam a produzir hortifrutigranjeiros agroecológicos que são comercializados na feira municipal, programas institucionais na comunidade e venda direta ao consumidor.

Nos espaços de assentamentos se percebe que a fase da juventude se molda por anseios e por muitas dúvidas, que recebem contribuição dos modos de vida de acordo com o espaço de criação e procedência da família. De acordo Fortunato et al., (s/d) os jovens envolvidos em disputas por terra, e que vivem no espaço dos assentamentos despertam a convivência social, política, cultural, sentimental e pessoal desde a infância, a qual passa ser uma condição necessária para sua inclusão na dinâmica cotidiana da comunidade assentada.

Assim desde da tenra idade os jovens despertam para a militância, por isso a necessidade de apreender sobre características e perfil dos jovens assentados se reflete na vivência de sujeitos envolvidos num processo de luta. Os jovens do Assentamento 8 de Junho tem sido contemplados com alternativas de trabalho por meio de políticas públicas destinadas 
a comunidade rural, os quais se juntam aos demais membros assentados para desenvolver atividades de cunho não-agrícola na garantia de permanecer no campo.

A perspectiva do jovem assentado se centra na formação política com vistas a contribuir no exercício das relações de poder/saber na comunidade. Além disso, constitui de modo conjunto, as alternativas que viabilizem a execução de políticas públicas voltadas para melhorias nas condições de vida e trabalho no assentamento (FORTUNATO et al., s/d). A pesquisa do trabalho se delimita por problemáticas de cunho político, econômico, social, educacional e sócio cultural que podem afetar e definir as opções de vida e formação da juventude assentada, com propósito de demonstrar a importância do jovem assentado enquanto sujeito social, participativo e político.

A estrutura do artigo se formata nesta introdução que contempla o objetivo; a metodologia do trabalho descrevendo o processo de pesquisa. Seguindo de um desenvolvimento contextualizando o papel que o jovem desempenha no meio rural, confrontando com resultados e discussões da pesquisa de campo realizado no Assentamento 8 de Junho, por fim as considerações finais.

\section{Metodologia}

O trabalho é oriundo do interesse de entender melhor sobre o envolvimento dos jovens em áreas de assentamento. Para o desenvolvimento da pesquisa foi selecionado o Assentamento 8 de Junho por ser verificado a participação de alguns jovens no processo de organização produtiva e social da comunidade.

A amostra do público utilizado para a pesquisa se constitui em jovens na faixa etária de 15 a 29 anos. Para esse trabalho se segue o padrão idade estabelecido pelas Nações Unidas e pela Comissão Econômica para a América Latina e o Caribe (Cepal) adotado por Abramovay et al., (1998). Ao levar em consideração o jovem sob aspectos: da situação do estado civil, condição maternidade/paternidade, as atividades públicas que estão centrados, como: escola, trabalho e lazer.

O trabalho possui variáveis de natureza qualitativa que exploram as condições de vida da juventude que mora no Assentamento 8 de Junho, a partir da visão dos jovens sobre local que contribuíram construir, onde residem e se este espaço proporciona ou sucumbe as idealizações e as necessidades conforme sua faixa etária. Para isso foram utilizadas bibliografias de material cientifico sobre o assunto em questão, também serviu como base para a construção do itinerário, questionários estruturados e entrevista ${ }^{2}$ semi-estruturada

\footnotetext{
${ }^{2}$ Com solicitação dos jovens entrevistados, nos depoimentos serão utilizados apenas códigos para diferenciar as falas dos entrevistados.
} 
aplicadas para 20 jovens escolhidos aleatoriamente. As entrevistas foram realizadas aos jovens nas dependências de sua propriedade rural no período de dezembro de 2012.

\section{Desenvolvimento rural, assentamento e juventude}

O papel desempenhado pela atividade no campo rumo ao seu desenvolvimento se atenta fortalecer a autonomia das famílias agricultoras, e favorecer as fontes de trabalho em termos sustentáveis. O desenvolvimento rural se detém numa dinâmica voltada para as práticas que visa reduzir a vulnerabilidade dos indivíduos e famílias no meio rural, por meio de ações que buscam a independência dos agricultores de agentes externos ${ }^{3}$, proporcionando autonomia dos mesmos em processos decisórios e fortalecendo perspectivas quanto ao seu desenvolvimento (CONTERATO, 2008).

Há peculiaridades no desenvolvimento rural que emergem como força, extensão e impacto de práticas agrícolas nos dias atuais e no padrão de vida rural dos moradores do campo (PLOEG et al, 2000). Dentre as diversas definições apresentadas a concepção de desenvolvimento rural, o conceito em síntese deve combinar o aspecto econômico, em que viabiliza o aumento em nível e estabilidade de renda da família, com o aspecto social, que se desenvolve em nível social aceitável perante a sociedade em geral, e ainda, combinar sua trajetória voltada para diversificação de atividades no espaço rural (KAGEYAMA, 2003).

O desenvolvimento rural tende consolidar o bem estar das famílias, combinando renda e atendimento das necessidades básicas ofertadas pelos bens públicos e serviços sociais. $\mathrm{O}$ desenvolvimento rural em termos conceituais se baseia num modelo alternativo destinado aos moradores do campo, dimensionado a um processo que multiplica as faces, os níveis e os atores, por congregar características tanto exógenas com endógenas oriundas dos ambientes em que se estabelecem as populações rurais. Por essa razão, "emerge a necessidade de se pensar e de se reconhecer o rural como lócus para seu desenvolvimento e não apenas como base material ou funcional de ampliação da produção e da produtividade agropecuária" (CONTERATO, 2008, p.55).

Ao contextualizar num trabalho sobre o tema assentamento, jovens e desenvolvimento passa ser uma referência que reporta-nos a constituição do assentamento, quanto a uma categoria de conquista da luta pela terra, em que no interior das propriedades, os jovens desenvolvem um cotidiano de atividades cada qual na sua dinâmica, se desdobrando junto a sua família para atender as suas necessidades básicas. A fim do desenvolvimento se tornar consequência da união pela luta empenhada sobre a terra, sendo o propulsor para buscar

${ }^{3}$ Os agentes externos são técnicos de empresas ou instituição responsáveis em prestar assistência ao agricultor. 
formas de complemento de renda por meio da esfera produtiva, além disso de descobrir futuras lideranças e desenvolver o espaço político. Sendo assim, o desenvolvimento rural do assentamento promove os espaços constantemente almejado pelos jovens do campo, para mostrar seu empenho trabalho rural, e na conquista do seu reconhecimento no espaço público.

A representação rural nas interfaces do assentamento abrange um rico ramo de atividades econômicas desenvolvidas por diversas práticas culturais, abarcando variados tecidos sociais. O que permite difundir a essência do desenvolvimento rural baseado no espaço, território e tendo como pilar de sustentação a família. Sobretudo a reforma agrária ditada pela pauta da renovada discussão de desenvolvimento rural, traz a tona o papel desempenhado pelo novo rural para sociedade como um todo.

Por isso se faz necessário compreender a história de vida dos jovens assentados na busca de um espaço privilegiado por muitos indivíduos na questão econômica, e na busca da sua consolidação no espaço social. E isso têm sido aos poucos incorporados pela juventude mediante a sua inserção no meio público, diante de uma condição de igualdade entre os esforços destinados a manter as necessidades da comunidade. O jovem se encontra numa situação e se coloca como ponto central de atenção pela bandeira na luta que adotaram, tomando a decisão de fazer escolhas, coragem e emancipação, mesmo sabendo o quanto custa essa iniciativa e que a mesma não ocorre de modo linear, com início, meio e fim.

Os fatores favoráveis a persuasão das atividades agrícolas e não-agrícolas está ligada ao ciclo demográfico das famílias, ao capital e terra, os quais estão relacionados a irregularidade da distribuição do tempo de trabalho na agricultura e a ausência dos meios de produção. A partir da relação do desenvolvimento rural com as propostas de análise social, trabalho e renda passaram enfatizar a ligação da agricultura com o sistema agroalimentar, as relações dos agricultores com o mercado de trabalho e os aspectos intrafamiliares decorrente do novo padrão de relações sociais e econômicas entre os assentados (SCHNEIDER, 2003).

\section{O papel do jovem que faz a diferença no meio rural}

Os jovens podem se tornarem agentes de transformação social e resgate do tempo, por serem a faixa etária que se distingue por características próprias em determinado grupo ou sociedade. Uma etapa da vida que não se refere apenas a passagem para a fase adulta, mas se determina pelo reconhecimento enquanto atores protagonistas do seu tempo, que atuam em 
ações visando à resolução de problemas do bem comum no ambiente que se fazem presentes (IIDAC; UNICEF, $2002^{4}$ apud OLIVEIRA, 2007).

A juventude envolvida na agricultura no meio rural se caracteriza pela aptidão agrícola intimamente associado a família (LAMARCHE, $1993^{5}$ apud OLIVEIRA, 2007). Para Castro (2005), a juventude tem conquistado a confiabilidade de investir no trabalho no campo por meio da hierarquia das relações familiares, principalmente se tratando do jovem que tem a concepção da imagem paterna como singular segmento dominante.

A exemplo da sucessão agrícola Abramovay et al., (1998) apresentam uma realidade vivenciada no Sul do Brasil, e muito comum ainda nas famílias agricultoras, devido ao aumento da expectativa de vida se prolonga o convívio entre pais e filhos. Ao mesmo tempo intervém na partilha de responsabilidade sob a propriedade, pois ao invés de haver o remanejamento da gestão do estabelecimento agrícola, os pais continuam dirigindo a propriedade, o que se torna um problema e uma ameaça na permanência juvenil no campo, por inibir seu talento e a sua capacidade administrativa. Pois ainda existem jovens que aspiram exercer a profissão de agricultor, sobre dois aspectos: o primeiro é perspectiva profissional, e o segundo por opção de vida.

A vida de um jovem no campo se caracterizada pela tranquilidade e ausência de marginalização favorecida pelas amizades, pelos valores como honestidade e simplicidade constituída num ambiente familiar. A juventude na comunidade rural tem acesso ao lazer mais simples e restrito a encontros com amigos, vínculos com vizinhos, bailes, jogos com pessoas mais próximas das famílias, entre outros (PREDIGER; MORTARI, 2009).

Para os jovens que buscam aprofundar seus estudos e conquistar uma profissão a tendência é a ligação com a área urbana. Tal necessidade se torna uma herança deixada pelos pais na garantia de vida melhor aos seus filhos, pela insegurança produtiva gerada na agricultura, alegando que o estudo lhe proporcionará vida melhor e lhe afastará da vida sofrida e dura do campo. Segundo Silva (2002), os jovens têm sido a categoria mais afetada pelas transformações do meio rural oriundas dos processos econômicos e da nova roupagem divulgada pelo desenvolvimento rural. Porque os jovens rurais começam muito cedo a participar das atividades produtivas da família, da interação com a parte financeira, conviver com a proximidade das dificuldades e lucros das atividades agrícolas desenvolvida por eles. Este tipo de exercício para Carvalho et al., (2009) se estende as atividades ligadas a comunidade, que juntas exigem que o jovem apreenda a lidar com responsabilidades e

\footnotetext{
${ }^{4}$ Instituto Internacional para o Desenvolvimento da Cidadanis; Fundo das Nações Unidas para a Infância. Políticas públicas e adolescência. E você? Curitiba, p. 4, nov. 2002.

${ }^{5}$ LAMARCHE, Hughes (Coord.). A agricultura familiar: comparação internacional. Tradução Ângela Maria NaokoTijiwa. Campinas: Unicamp, 1993. Tradução de: L' agriculture familiale.
} 
desperte o desejo de melhorar o ambiente que trabalha, vive e convive, que possam num futuro atender as necessidades básicas de sua sobrevivência.

Portanto, Silva (2002) ressalta que é necessário compreender as similaridades entre os jovens e o ambiente que convivem, vivem e trabalha, para enfim entende-las nas diferenças sociais, isto é, cada jovem se mostra diferente e pode ser identificado como tal.

\section{Resultados e discussões}

\section{Apontamentos sobre a ocupação da área do Assentamento 8 de Junho - período do acampamento Rio Leão}

As famílias que passaram pelo período da ocupação da Fazenda do Rio Leão afloraram e entrelaçaram na memória lembranças, sentimentos de medo, de pudor $^{6} \mathrm{e}$ de vergonha no momento da ocupação da sede da fazenda. Pois tiveram momentos de escassez de comida, instalações precárias e sofrimento com a pressão dos pistoleiros. Nas instalações próximas da rodovia eram difíceis os meios para atender as necessidades básicas e realizar os hábitos higiênicos. A persistência da insegurança e a demora pela conquista de um pedaço de terra, o desafio de seguir em frente e deixar a família, a vergonha de muitas vezes recorrer a parentes, isso tudo fez parte do processo que durou até a conquista do lote.

$\mathrm{Na}$ época do acampamento, a região escolhida para se instalar era caracterizada pela atividade pecuária. Uma área ampla que residia em torno de 20 famílias, nesse espaço restou poucos habitantes, sem motivos aparentes os moradores não resistiram à ocupação e foram abandonando as terras. Em 8 de junho de 1997, a frente do portão da Fazenda Rio Leão localizada as margens da rodovia BR 158 em Laranjeiras do Sul - Paraná, um número de 17 famílias ergueram seus "barracos", edificando o marco inicial da estrutura de ocupação. Desse modo, em pequenos traços o trecho da rodovia foi tomando contornos de acampamento.

Das famílias e outros grupos que vieram posteriormente para a ocupação da fazenda, as relações de casais ou pais e filhos foram abaladas, pois esposas conviveram longe de seus parceiros, filhos moraram longe de seus pais. Como se observou na pesquisa foram poucos indivíduos que vieram acampar em família, e os que não ocorreram dessa forma, os cônjuges/pais vieram primeiro para acampar nas margens da rodovia, dali por tempo indeterminado com aquisição de uma precária estrutura de um barraco, e devido à obrigação de atender as necessidades familiares, as mulheres e os filhos se juntavam ao seu parceiro/pai embaixo da lona.

\footnotetext{
${ }^{6} \mathrm{O}$ termo se refere ao sentimento de vergonha por ferir sua decência como ser humano.
} 
Como grande parte das famílias não era proprietária da terra onde morava, ou dividia-a com outros parentescos favorecia as dificuldades para auto sustento. Por isso, o ato de acampar associado com o processo de se desfazer das benfeitorias já instaladas era feito com dificuldades materiais e emocionais. $\mathrm{O}$ fato de aderir o acampamento devia-se as más condições financeiras para investir numa propriedade agrícola. As dificuldades financeiras ainda permaneceram no período de acampamento, por falta de alternativas produtivas que sustentasse a família, tendo que se sujeitar a recorrer a parentes ou pessoas próximas.

As tarefas domésticas também não eram favorecidas pela estrutura do barraco, que era apenas utilizado como espaço para guardar os móveis, realizar as refeições, refúgio das intempéries climáticas e abrigo para dormir. Por isso, o simples ato de lavar roupa e cuidados higiênicos foram considerados um percalço na vida cotidiana das famílias acampadas. Esses tipos de situações foram amenizados pelas reuniões e trabalho de grupos, considerado as soluções encontradas pelas famílias para persistir na condição de acampada.

As primeiras atividades coletivas, reuniões e celebrações ocorriam em lugar improvisado. Esse modo de organização no acampamento foi uma estratégia aplicada pelo movimento para elevar o capital social, proveniente do trabalho coletivo dos acampados por meio da colaboração e cooperação da comunidade.

O fato de acampar se tornou uma recordação para os atores envolvidos, e passou a ser entendido como um momento de abertura para um cotidiano coletivo entre famílias. Sob a consciência de sua importância para a estruturação do assentamento, da produção agrícola e do suporte emocional.

Em 30 de janeiro de 1998 havia no total mais de 73 famílias no local ocupado, as quais permaneceram num período de quatro anos. Nesse cotidiano recria-se um cenário de celebrações de nascimentos, batizados, mortes, novas amizades, desentendimentos entre vizinhos, num adjetivo de adesão/desistência e encorajamento/desestímulo de continuar no acampamento.

Este mesmo período deixou marcas, como: as perseguições por parte da polícia, duelos com pistoleiros da fazenda, e prisões de alguns acampados, tais motivos foram primordiais para que alguns membros acampados fossem desistindo do projeto de conquista a terra. Segundo informações dos entrevistados a sustentação do acampamento se expressa numa decisão pessoal, familiar e acima de tudo coletiva, que pode sofrer influencias pelo decorrer do processo de acampar.

Além disso, no período de acampamento houve uma grande transição de número de membros devido à demora do Instituto Nacional de Colonização e Reforma Agrária - INCRA liberar os lotes às famílias. O longo período que seguiu o acampamento até liberação da terra foi determinante para a permanência dos atores que estavam instalados nas intermediações da 
rodovia. Desse modo, em novembro de 1999 foi determinado a desapropriação de terra e em abril de 2000 foi emitido o documento de posse, que possibilitou na época assentar 74 famílias.

\section{A juventude no Assentamento rural 8 de Junho}

Durante a pesquisa não se esperava encontrar um número grande de jovens engajados em atividades voltadas para desenvolvimento rural do Assentamento 8 de Junho. Isso porque na maioria das vezes, os jovens são entendidos como meros coadjuvantes no interior da propriedade rural e no espaço público do assentamento.

Os jovens abordados para entrevista abrangem a faixa etária de 17 anos a 26 anos, com escolaridade variando entre ensino médio a ensino superior incompleto. Todos os jovens entrevistados declararam in loco o desejo de exercer uma profissão mais qualificada que possibilite reverter o conhecimento em melhorias ao assentamento, isso tem se tornado possível devido ao anseio de continuar os projetos que o assentamento tem viabilizado por intermédio dos assentados de faixa etária mais avançada que já pensam no futuro desses jovens.

Segundo os jovens entrevistados, a palavra "família" representa como um importante lugar de residência, a unidade produção e consumo, e acima disso incorpora uma rede de parentesco. Os jovens são vistos pelas famílias assentadas rurais como meio de reproduzir os seus valores e dar continuidade a ideologia ensinada pelos movimentos sociais. Por isso, a família incentiva o jovem a continuar morando na proximidade, para evitar a ausência ou redução de mão de obra, e transformações no lote temendo que cultura do assentamento desapareça.

O tamanho territorial dos lotes do assentamento tem influenciado na permanência dos jovens depois de adultos, tal fato se tornou evidente nas informações coletadas na pesquisa. Em que 55\% das famílias têm de três a quatro filhos, e 35\% ainda tem um filho dependente que pode ser dependente financeiro, ou dependente para atender as necessidades básicas, ou ainda, dependentes de ambas. Como mostra a tabela 1, tanto na dependência financeira como no atendimento de necessidades básicas os homens prevaleceram, e pelos mesmos se apresentarem mais dependentes do que as mulheres.

Tabela1: Número de filhos e sua situação na família Assentamento 8 de Junho 


\begin{tabular}{|c|c|c|c|c|c|c|c|c|c|c|c|c|c|c|c|c|}
\hline \multirow{2}{*}{$\begin{array}{l}\text { Quan } \\
\text { tidad } \\
\text { e de } \\
\text { filhos }\end{array}$} & \multicolumn{2}{|c|}{$\begin{array}{l}\text { Total de } \\
\text { filhos }\end{array}$} & \multicolumn{2}{|c|}{$\begin{array}{c}\text { Filho } \\
\text { depende } \\
\text { nte }\end{array}$} & \multicolumn{6}{|c|}{$\begin{array}{l}\text { Total de famílias c/ } \\
\text { filhos dependência } \\
\text { financeira }\end{array}$} & \multicolumn{6}{|c|}{$\begin{array}{c}\text { Total de famílias c/ } \\
\text { dependência necessidades } \\
\text { básicas* }\end{array}$} \\
\hline & Fam & $\%$ & $\begin{array}{c}\text { Fa } \\
\text { m }\end{array}$ & $\%$ & $\mathbf{M}$ & $\%$ & $\mathbf{H}$ & $\%$ & $\mathbf{T}$ & $\%$ & $\mathbf{M}$ & $\%$ & $\mathbf{H}$ & $\%$ & $\mathbf{T}$ & $\%$ \\
\hline 0 filho & 4 & 20 & 4 & 20 & - & - & - & - & - & - & - & - & - & - & - & - \\
\hline 1 filho & 1 & 5 & 7 & 35 & 4 & 57 & 4 & 80 & 8 & 67 & 5 & 50 & 9 & 82 & 15 & 68 \\
\hline $\begin{array}{c}2 \\
\text { filhos }\end{array}$ & 4 & 20 & 5 & 25 & 2 & 29 & 1 & 20 & 3 & 25 & 2 & 20 & 1 & 9 & 3 & 14 \\
\hline $\begin{array}{l}3 \text { a } 4 \\
\text { filhos }\end{array}$ & 11 & 55 & 4 & 20 & 1 & 14 & - & - & 1 & 9 & 3 & 30 & 1 & 9 & 4 & 18 \\
\hline Total & 20 & $\begin{array}{c}10 \\
0\end{array}$ & 20 & $\begin{array}{c}10 \\
0\end{array}$ & 7 & $\begin{array}{c}10 \\
0\end{array}$ & 5 & $\begin{array}{c}10 \\
0\end{array}$ & $\begin{array}{l}1 \\
2\end{array}$ & $\begin{array}{c}10 \\
0\end{array}$ & $\begin{array}{l}1 \\
0\end{array}$ & $\begin{array}{c}10 \\
0\end{array}$ & $\begin{array}{l}1 \\
1\end{array}$ & $\begin{array}{c}10 \\
0\end{array}$ & 22 & $\begin{array}{c}10 \\
0\end{array}$ \\
\hline
\end{tabular}

Fonte: Pesquisa de campo, 2012.

Legenda: Fam.: Família; M: Mulher; H: Homem; T: Total.

* A dependência dos filhos com relação as necessidades básicas fornecidas pelos pais tem relação a alimentação, moradia, escola, saúde, higiene entre outras que forem possíveis de serem atendidas pelas famílias.

Esses resultados se equiparam com estudo de Abramovay et al., (1998), pelo fato da permanência dos filhos na propriedade rural interferir nos padrões sucessórios das famílias, e pelas diferenças de tratamento entre os filhos de sexo feminino e masculino. Isso se torna resultado e tendência no meio rural, por causa do incentivo dos pais para que os filhos homens permaneçam na atividade rural e que cuidem dos pais ao envelhecer, enquanto as filhas mulheres pela invisibilidade dos préstimos na propriedade são incentivadas a saírem em busca de melhores oportunidades de sobrevivência. Pela conversa com os jovens assentados se confirmou existência de diferenças na permanência entre jovens do sexo feminino e sexo masculino no campo, para as jovens, os pais têm incentivado a sua migração para a cidade para garantir sua sobrevivência, deixando como já foi apresentada na pesquisa a propriedade a sucessão do homem. Essa situação acontece pela a inviabilidade do trabalho no lote do assentamento proporcionar sustento a todos os filhos, e sua inviável repartição pelo tamanho reduzido de terra. A família para compensar a incerteza de um futuro na agricultura tem incentivado os filhos estudarem para buscar melhores condições de trabalho.

Entre os projetos desenvolvidos no Assentamento 8 de Junho se encontra a dedicação de incluir as jovens assentadas num trabalho realizado pelas mulheres assentadas na panificadora comunitária, o mesmo serviu de suporte para superar as dificuldades, bem como 
serviu de ideias para projetos de geração de renda e oportunidades empregatícias. Sendo algo inspirador para organização da atividade não-agrícola e para os jovens que acompanharam esse processo, e tem colhido frutos por meio dos cursos e formação disponíveis aos assentados, uma organização que evolui junto com o assentamento.

Para os jovens entrevistados a renda para sua sobrevivência depende do trabalho da família, isso faz com que não exija dele a obrigação de auto sustento. Isso facilita para que o jovem possa se dedicar as atividades da comunidade de modo voluntário, por isso, se percebeu a facilidade que a juventude tem para se dedicar em atividades do Assentamento 8 de Junho. Com relação às atividades comunitárias destinadas aos jovens, segundo informações dos entrevistados não existe um grupo separado e destinado a fim de realizar atividades especificas para jovens, como descreve um jovem entrevistado:

$\mathrm{Na}$ época de acampamento eu era criança não participava muito. O grupo de jovens era bem ativo, hoje a gente não tem um grupo de jovens especifico, que tem um nome, mas acho que a juventude contribui em tudo aqui se tem uma festa a juventude esta ajudando, se tem campeonato, em tudo até na cozinha a juventude esta auxiliando (JOVEM M, 2012)

Como foi possível observar nas entrevistas, o perfil dos jovens que contribuem nas atividades coletivas e atividades esporádicas no assentamento são aqueles que nasceram ou vieram crianças e cresceram no acampamento, que permanecem trabalhando com a família, que tendem se dedicar exclusivamente a estudar, e tem compromisso de ajudar nas atividades da propriedade, devido desobrigação de atender a trabalho com hora fixa ou compromisso com emprego e renda. Por isso o jovem entrevistado relata que:

Eu acho que o jovem desde o tempo de acampamento sempre teve espaço aberto na comunidade de hoje, inclusive não existe um grupo formado que se reuni todo fim de semana. Na comunidade: acho que a participação também faz a diferença nasce dentro que não viveu na fase de acampamento, mas que esta hoje como adolescente. O jovem no assentamento acho que a questão desde da consciência tem de formação política do ser humano tem uma visão melhor das coisas (JOVEM J, 2012).

Entre atividade geradora de renda externas a propriedade para algumas famílias assentadas existem a feira municipal de agricultores, a panificadora comunitária e queijaria do assentamento, sendo espaços que os jovens atuam, são colaboradores, e por intermédio da universidade local realizam atividades do projeto de extensão; enfim, na possibilidade e 
conforme a aptidão juvenil aparece em atividades do assentamento. Sendo as atividades que favorecem pela facilidade de comunicação, desenvoltura, contribui para futuro profissional.

Dos jovens que foram entrevistados todos eram crianças quando chegaram na fazenda ocupada, e acompanharam desde início todo o processo de acampamento até assumir a condição de assentado junto dos seus pais. Uma jovem que se mudou de Santa Catarina com sua mãe para o acampamento com cinco anos, pois seu pai já estava acampado na proximidade da rodovia, onde sua família morava na área rural como arrendatários, relata as dificuldades que passou quando chegou ao acampamento:

A gente veio pra cá e ai eu perguntava pra mãe: como era lá num barraco essas coisas: tem assoalho? Tem tijolo? Sei lá! Não imaginava, era criança, ai ela falou que não tem, mas ela também não sabia como era o barraco, ai tá! Chegamos era um dia bem chuvoso, assim olhei a todos aqueles barracos assim grudadinho noutro cheio de pau em cima pra segura a lona por causa do vento, eu falei mãe é aqui? Ela é aqui, ai cheguei no barraco nosso, onde o pai estava, porque ele veio na frente, nós viemos depois, tinha um borraio que era o fogão feito no chão bem baixinho, o chão cheio de valeta por causa da chuva, entrei no barraco cheio de valeta. Meus Deus! E eu achando que era tudo de tijolo assoalho, assim que era de lona eu sabia, mas o assoalho achei que sei lá, tinha nenhuma idéia, chegar aquele barraco cheio de valeta no chão, de pau em cima das lonas, nossa Senhora do céu da terra... até hoje me lembro não era conforto mas era uma casa, tinha era uma que não era nossa, mas é que a gente morava de agregado lá (JOVEM J, 2012).

O relato da jovem é marcado pelas dificuldades que passou quando criança, com isso seus projetos de vida passa por uma melhor compreensão das condições históricas e materiais da vida cotidiana de sua família.

A história de uma jovem que participou desde início do acampamento e vivenciou o processo de ocupação quando tinha 13 anos. Sua família morava na área rural do município próximo do assentamento, a terra era dividida em oito famílias todos parentes consanguíneos, mas seu pai por ter uma ligação com os movimentos sociais favoreceu para que a família se engajasse à causa do Movimento dos Trabalhadores Rurais Sem Terra - MST, chegando até ao Assentamento 8 de Junho. Sua contribuição é influente na participação/organização da feira municipal de agricultores, como estudante universitária se envolve trabalhando difundindo as ideologias agroecológicas. Por conta da oportunidade de trabalho já exerceu a função de técnica agropecuária em que prestava assistência ao assentamento e intermediava com o instituto e entidades responsáveis. Assim ela fala: 
Na verdade meus tios já tinham vindo e meu pai ainda não tinha vindo trabalhar, mais eu e meu irmão tinha vontade de vir pro acampamento pela própria história do movimento e tal porque o pai era ligado ao Sindicato dos Trabalhadores Rurais. Nós morávamos no Rio Bonito e lá o tio só tinha um pouquinho de terra mesmo, e então única forma de consegui mesmo, ele já trabalhava de empregado porque só o que tinha não dava e daí nós viemos pro acampamento. Esse tempo de acampamento é difícil, não é fácil mesmo né, só que é uma escola o que se aprende a solidariedade, companheirismo entre as pessoas, aprender a conviver mais com as pessoas (JOVEM S, 2012).

Diante desse depoimento se percebe que o jovem ao crescer junto com as dificuldades da família e sob as perspectivas dos movimentos sociais - o fato de não ter algo que pertencia a eles tende sobreviver numa a situação de desapego a coisas materiais, a convivência de lutar por algo muito cedo não faz diferença de idade, a situação do acampamento impõem as crianças a responsabilidade muito cedo de conviver com situações de risco faz com que jovens do campo se tornem instruídos a ideologias dos movimentos sociais. Outra jovem filha que se mudou para o acampamento com cinco anos encontrou um lugar especial para uma criança, devido a proximidade dos barracos facilitava a diversão na época. Também ao mesmo tempo ao se engajar com a família no acampamento contribuiu com a integração no movimento, como ela mesmo relata:

Eu acho que é a questão da organização mesmo é uma coisa que marca bastante imagina eu com 5 aninhos já viajava longe né. Foi participando tipo pra Brasília para encontro, então essa questão da organização do MST que a gente tem. É uma coisa que marca pra sempre (JOVEM S, 2012).

Cabe ressaltar a visão que os jovens têm sobre o espaço do assentamento como meio de oportunidade para permanência da juventude no campo, e esses jovens contribuírem para o desenvolvimento e melhorias na comunidade rural, como tal:

Os próprios jovens não dão pra se queixar mesmo, nós também não podemos querer reclamar de não ter oportunidade porque tem, tem oportunidade de estudar, tem oportunidade de trabalhar. Então na verdade nós contribuímos com o assentamento e o assentamento está contribuindo com nós (JOVEM S, 2012).

Neste caso existe uma percepção clara da importância das políticas públicas implementadas no assentamento potencializadoras da reforma agrária. A convivência com desenvolvimento rural e a atuação do jovem no campo como possibilidades de melhoria da 
qualidade de vida nos assentamentos, e agricultura familiar como alternativa de desenvolvimento sustentável.

Os jovens enxergam o espaço do assentamento aberto a todos os grupos sociais, pois todos são essenciais na condução e desenvolvimento da comunidade, do mesmo modo que cada um tem sua função no interior do assentamento, desde divulgação das atividades até o seu desenvolvimento. Como fala uma jovem:

Na minha visão, ninguém bom tem na comunidade, não tem espaço limitado o que é das mulheres o que aqui é dos homens, o que é das crianças é todo mundo junto é uma comunidade e num lugar pro jovem não tem essa divisão todo mundo junto (JOVEM F, 2012).

Com relação aos fatos e acontecimentos que marcaram a vida da juventude durante a transição do acampamento para assentamento, se remete as dificuldades que passaram para permanecer na área ocupada. Como demonstra a fala do jovem:

\footnotetext{
Nesse negócio de enfrentamento contra polícia e as festas acho que tudo unia as pessoas, eu não digo que sempre houve uma separação acho que sempre tem a separação de tarefas, na verdade a mulher fica na casa e o homem faz tal coisa trabalha fora, mas acho que no assentamento sempre foi unido na época de acampamento tudo muito unido homem, mulher e criança lutavam junto pra consegui a terra (JOVEM D, 2012).
}

Isso se remete na ajuda, união e solidariedade que os acampados demonstraram para as dificuldades:

Foi a convivência todo mundo junto ali se criamos bem dizer todo mundo junto, o que faltava para um o outro daí dividia, a partilha entre as pessoas né. Porque teve épocas que alguém não tinha feijão pra come ou era só arroz ai o outro vizinho que tinha feijão emprestava feijão para outro que só tinha arroz (JOVEM D, 2012).

\section{Contudo:}

Eu acho que, por exemplo, as mulheres desde inicio sempre se reuniram no grupo das mulheres para discutir. As mulheres sempre tiveram presente desde inicio do acampamento e fizeram a diferença, as mulheres com as crianças, porque gera mais impacto acho: que isso, se tivesse só homem no acampamento seria bem diferente. E a organização que elas tinham também porque sempre faziam artesanato, principalmente pra aquelas famílias que tinham mais dificuldade, no inverno faziam bastante crochê, cobertor de lã (JOVEM S, 2012). 
Os jovens se preocupam com o processo coletivo de desenvolvimento e melhorias da comunidade, em suma, esses assentados se mostram especiais, por serem uma minoria que tende permanecer na área rural de um assentamento e que se mostram ativos fazendo a diferença.

\section{Considerações finais}

Conforme o propósito do objetivo trabalhado, a vida dos jovens pertencentes do Assentamento 8 de Junho se difere da realidade de outros jovens que residem na área rural ou em assentamentos/acampamentos de sem-terra por optarem a permanecer no campo, mesmo tendo acesso a área urbana. Por meio, de contribuir com o assentamento ao se preparar profissionalmente, e estarem junto dos adultos trabalhando e se inserindo na esfera pública da comunidade.

Dessa forma, os resultados da pesquisa se apresentam diferentes do que a literatura e pesquisas de outros autores sobre jovens, as informações demonstraram que a juventude procura alcançar sempre a possibilidade de permanecer no campo. Mesmo que esse público residindo em áreas assentadas sofra com a dependência da produção dos pais e incerteza de terem terra para seu sustento e da família.

Esse tema ainda precisa ser aprofundado no âmbito dos assentamentos, principalmente com este público que tende a contribuir e ser o futuros propulsores das ideologias dos movimentos sociais. 


\section{Referências Bibliográficas}

ABRAMOVAY, R; SILVESTRO, M; CORTINA, N; BALDISSERA, T; FERRARI, D; TESTA, V. M. Juventude e agricultura familiar: desafios dos novos padrões sucessórios. Brasília, UNESCO, 1998.

CARVALHO, D. M; SANTOS, A. B; SOUZA JÚNIOR, J. P; FERRER, M. T. Perspectivas dos jovens rurais: campo versus cidade. In: Congresso Sociedade Brasileira de Economia, Administração e Sociologia Rural, 47, 2009. Anais... Porto Alegre: SOBER, 2009.

CASTRO, E. G. de. Entre ficar e sair: uma etnografia da construção social da categoria jovem rural. 2005, 380f. Tese (Doutorado em Antropologia Social) - Universidade Federal do Rio de Janeiro, Rio de Janeiro, 2005.

CONTERATO, M. A. Dinâmicas regionais do desenvolvimento rural e estilos de agricultura familiar: uma análise a partir do Rio Grande do Sul. 2008, 290f. Tese (Doutorado em Desenvolvimento Rural) - Universidade Federal do Rio Grande do Sul, Porto Alegre, 2008.

FORTUNATO, M. L; MOREIRA NETO, M; BUENO, R. J; OLIVEIRA, B. S; SARMENTO, F. C; CAMILO, J. P. P; LIRA, P. R; AMORIM, J. M. S; NASCIMENTO, J. M. Relações de poder/saber: protagonismo de jovens em assentamentos rurais do Alto Sertão paraibano. In: Encontro Unificado de Ensino, Pesquisa e Extensão da Universidade Federal de Campina Grande, s/d. Anais... Campina Grande: UFCG, s/d.

Instituto Brasileiro de Geografia e Estatística. Paraná cidades. Rio de Janeiro: IBGE, 2009.

KAGEYAMA, A. Diversificação das rendas nos domicílios agrícolas no Brasil, 1992 e 2001. Revista Economia e Sociedade, Campinas, v.12, n.1, p. 65-86, jan./jun. 2003.

OLIVEIRA, R. de S. Expectativas quanto ao trabalho: um estudo com jovens que vivem em assentamento rural no município de São Francisco do Pará. Revista Amazônia: Cia. \& Desenvolvimento, Belém, v. 2, n. 4, p. 105- 117, jan./jun. 2007.

PLOEG, J. D; RENTING, H; BRUNORI, G; KNICKEL, K; MANNION, J; MARSDEN, T; ROEST, K; SEVILLA-GUZMÁN, E; VENTURA, F. Rural Development: From Practices and Policies towards Theory. Sociologia Ruralis, v. 40, n.4, p.391-408, Oct. 2000.

PREDIGER, S; MORTARI, E. C. M. A representação social e a construção das identidades entre os jovens rurais: iguais ou diferentes? In: Salão de Iniciação Científica, 10, 2009. 


Anais... Rio Grande do Sul: PUCRS, 2009.

<www.pucrs.br/edipucrs/...Sociais.../70740-SOLANGE_PREDIGER.pdf〉. Acesso em junho de 2011.

SCHNEIDER, S. A pluriatividade na agricultura familiar. Porto Alegre: Editora da UFRGS, 2003.

SILVA, V. Jovens de um rural brasileiro: socialização, educação e assistência. Caderno Cedes, Campinas, v. 22, n. 57, agosto/2002, p. 97-115. 